\title{
الإطار التحليلي للطاقة المتجددة
}

عبد الله خالا براك خلف براك

طالب دكتوراه بمعهد البحوث والدراسات الأفريقية- جامعة أسوان بران

$$
\text { محمد عبد الوهاب ابو نحول }
$$

أستاذ الإقتصاد الزراعى - كلية الزراعة - جامعة أسيوط

\section{رباض اسماعيل مصطفى رياض كاض}

أستاذ الإقتصاد الزراعى - كلية الزراعة - جامعة العريش

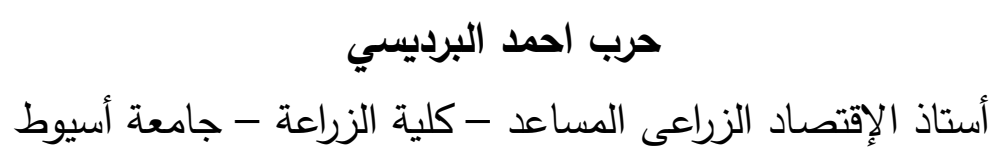




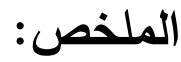

تهدف الدراسة الي شرح الاطار التحليلي للطاقة البديلة، توصلت الدراسة علي

الرغم من أن التطورات التكنولوجية كان لها دورا هام في رفع كفاءة الطاقة المتجددة، إلا أنه لازال الطاقة المتجددة تسهم بنسبة منخفضة في الاستهلاك العالمي للطاقة، كما أن مصادر توليد الطاقة المتجددة لاسيما الطاقة الثمسية والرياح والطاقة الحرارية لازالت تسهم بنسبة محدودة في تكوين الطاقة المتجدة مقارنة بمساهمة الطاقة الكهرومائية في تكوين الطاقة المتجدة، كما لاتزال مصادر الطاقة المتجددة تواجه عدة تحديات مالية وتشريعية واقتصادية لضمان استمرار نموها وتوسيع استخدامها عالميا. الكلمات الإفتتاحية: الطاقة المتجدده - التتمية المستدامة - الوطن العربى

\section{Abstract}

\section{Renewable Energy Analytical Framework}

The study aims to explain the analytical framework of alternative energy, The study found that although technological developments have had an important role in raising the efficiency of renewable energy, renewable energy still contributes to a low percentage in global energy consumption, Also, renewable energy generation sources, especially solar, wind and thermal energy, still contribute to a limited percentage in the formation of renewable energy compared to the contribution of hydropower in the formation of renewable energy, Renewable energy sources are still facing several financial, legislative and economic challenges to ensure their continued growth and expansion of their use globally.

\section{- 1- 1 - 1 مقدمة}

تُعد الطاقة المتجددة وسيلة لتخفيف انبعاثات الغازات الدفيئة وتحقيق فوائد اجتماعية مباشرة وغير مباشرة، حيث يؤدي الاهتمام بالطاقة المتجددة إلي مساعدة البلدان على إنشاء شبكات طاقة حديثة وآمنة، ويحفز انخفاض تكاليف الطاقة النظيفة بشكل كبير في هذا التحول، بالاضافة إلي أن التكنولوجيات المتطورة مثل الشبكات 
الذكية والعدادات الذكية وأنظمة البيانات الجيومكانية قد أدت إلي تحولات رئيسية في مجال الطاقة، ترتب عليها ارتفاع مؤشرات الطاقة المتجدة عالمياً من حيث الاستمارات والقدرات وتكاملها مع بقية القطاعات الاخري. تجدر الاشارة إلي أن هناك العديد من الدراسات الساقة التي تناولت الطاقة

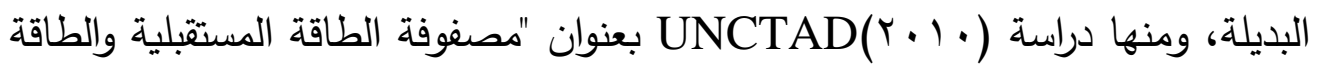

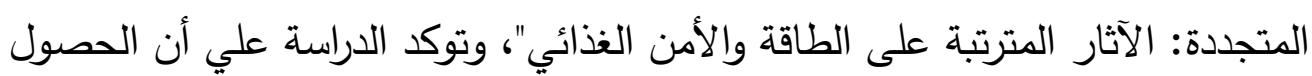

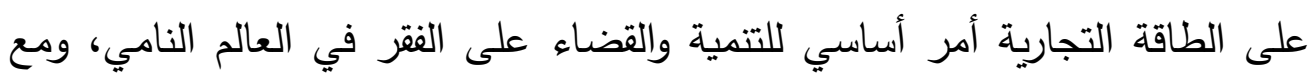

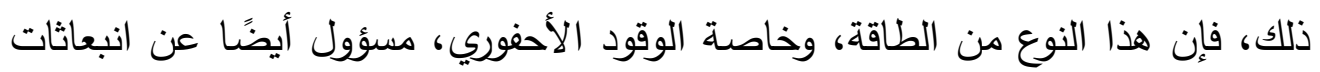
غازات الاحتباس الحراري، التي تهدد استقرار النظام المناخي، لذلك من الضروري إدخال مصادر طاقة منخفضة الكربون في مزيج الطاقة الوطني والعالمي، مع التخلص من الاعتماد على الوقود الأحفوري حتى تتمكن البلدان من تحقيق أمن الطاقة دون تعريض الجهود المبذولة لتحقيق الأمن الغذائي للخطر . كما تقدم مشاريع الطاقة المتجدة، ولا سيما طاقة الرياح والطاقة الشمسية، مزايا بيئية مقنعة بالمقارنة مع طاقات الوقود الأحفوري في توليد الطاقة، بما في ذلك

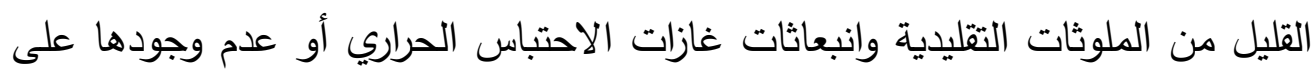
الإطلاق، ومع ذلك، تواجه مشاريع الطاقة المتجددة تحديات خطيرة تتافس مع مشاريع الطاقة التقليدية التي تعمل بالوقود الأحفوري ، حيث لا تزال التقنيات تتطور وظلت التكاليف مرتفعة نسبيًا.

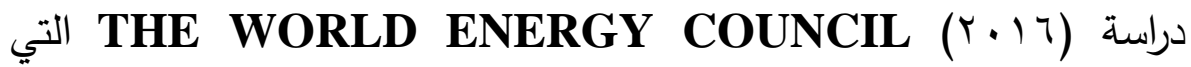

توصلت إلي أن السنوات الخمس عشرة الماضية شهدت تغيرًا غير مسبوق في استهلاك موارد الطاقة، كما أدى النمو المرتفع غير المتوقع في سوق الطاقة المتجددة من حيث الاستثمار والقدرة الجديدة ومعدلات النمو المرتفعة في البلدان النامية إلى تغيير المشهد العام لقطاع الطاقة، وتؤكد الدراسة علي نمو الموارد غير التقليدية والتحسينات في التطور التكنولوجي لجميع أشكال موارد الطاقة، وقد ساهم ذلك في انخفاض الأسعار 
وزيادة الفصل بين النمو الاقتصادي وانبعاثات غازات الدفيئة، كما حققت معظم البلدان مزيجًا أكثر تتوعًا للطاقة مع نمو في ملكية المجتمع وتطور الثبكات الصغيرة. تستهدف الدراسة الحالية شرح الاطار التحليلي للطاقة المتجددة، إذ تقوم الدراسة الحالية علي فرضية مفاداها أنه لازال مساهمة الطاقة البديلة في الطاقة العالمية منخفضة، كما أن الدراسة تعتمد علي المنهج الاستقرائي في جمع البيانات اللازمة في شرح الاطار التحليلي للطاقة البديلة، وقد تم تقسيم الدراسة إلي 17 اجزاء بالاضافة الي المقدمة، حيث يشمل الجزع ا.Y توضيح للاهمية النسبية للطاقة المتجددة، بينما يشتمل الجزء ا.ب توضيح للطاقة المتجدة في نطاق أهداف التتمية

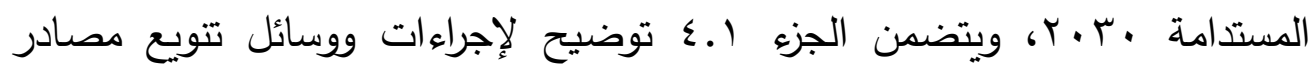
الطاقة المتجددة، ويبين الجزء المتجددة، اما الجزء الاخير يتضمن الخلاصة.

\section{: الاهمية النسبية للطاقة المتجددة}

لقد ساهمت التطورات التكنولوجية في رفع كفاءة الطاقة المتجددة، والتي يتوقع أن تكون بديلاً لموارد الطاقة غير المتجددة، لاسيما للبلدان التي تخلفت في انتاج الطاقة، حيث يمكن لهذه البلدان الاعتماد علي الطاقة المتجدة لمواجهة تحديات الطاقة لايها، ويوضح الثكل (1) الاهمية النسبية لموارد الطاقة المتجددة والغير المتجددة حسب الاستهلاك العالمي. يتبن من الثكل (1) أنه لازال النفط والفحم المصدر الاساسي والاول لاستهلاك العالمي حيث أن كل من النفط والفحم يسهمان بأكثر من نحو . ب\% من الاستهلاك العالمي للطاقة، فالنفط فقط يسهم بنحو r.؟r\% من الاستهلاك العالمي

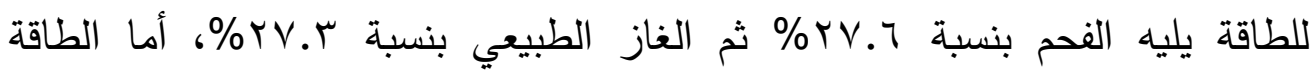

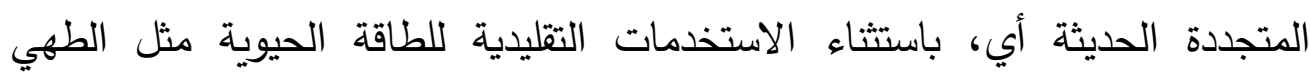
المرتبط بتأثيرات صحية سلبية كبيرة، أصبحت تسهم بنحو ع. . ا ( من مصادر الطاقة وهي نسبة مرتفعة نسبيا أي، بالنسبة لمثيلتها في العقود الماضية، وتأتي مساهمة 


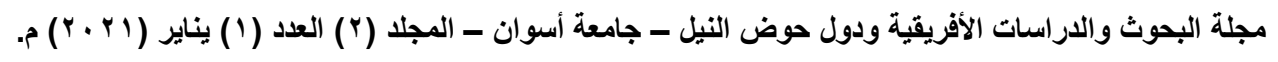

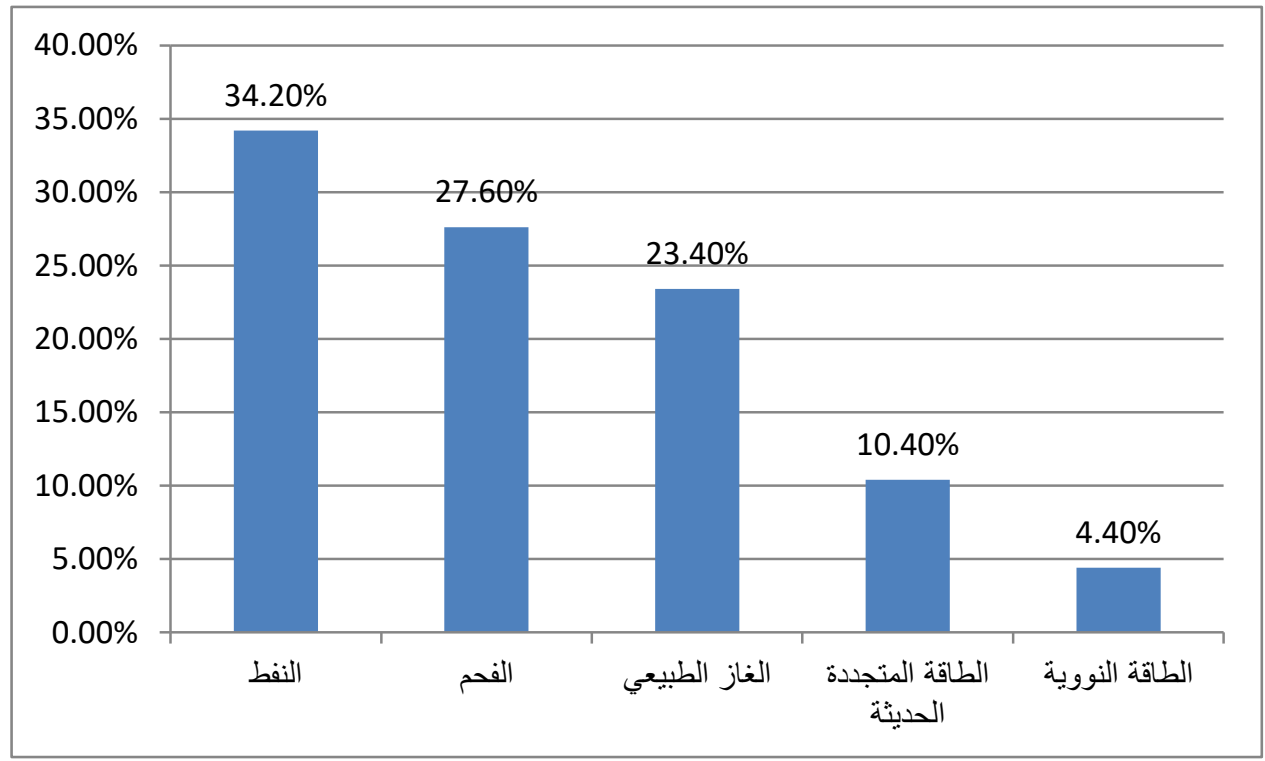

الطاقة النووية في الاستهلاك العالمي للطاقة في المرتبة الاخيرة بنسبة بلغت نحو .\%乏.乏

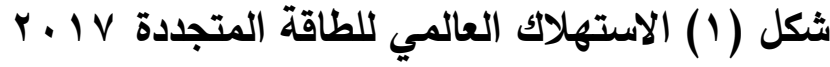

Source: (Elavarasan, 2019:2)

وجدير بالذكر علي الرغم من أن الاحصائيات تثير إلي أن اجمالي

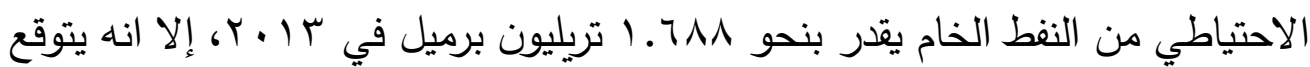
أن يستمر إجمالي احتياطي النفط الخام لنحو r.به عام فقط، بافتراض استمرار معدل

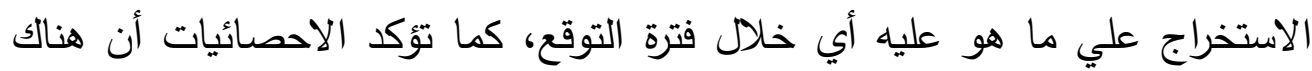
نحو 1. 1 تريليون طن من احتياطيات الفحم المؤكدة في جميع أنحاء العالم، والتي سوف تستمر حوالي .10 سنة. كما ستستمر احتياطيات الغاز حتى or عامًا (Elavarasan, 2019:2) ومن ثم ضرورة العمل علي تنمية مصادر الطاقة المتجدة، لاسيما الطاقة الثمسية والطاقة الحرارية والرياح التي لازالت تسهم بنسبة محدودة في تكوين الطاقة المتجدة مقارنة بمساهمة الطاقة الكهرومائية في تكوين الطاقة المتجدة كما هو موضتح في الثكل (r) 


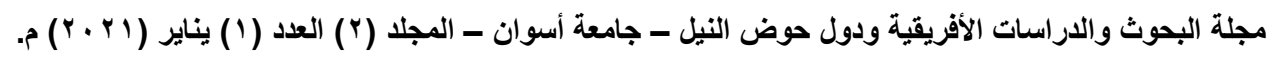

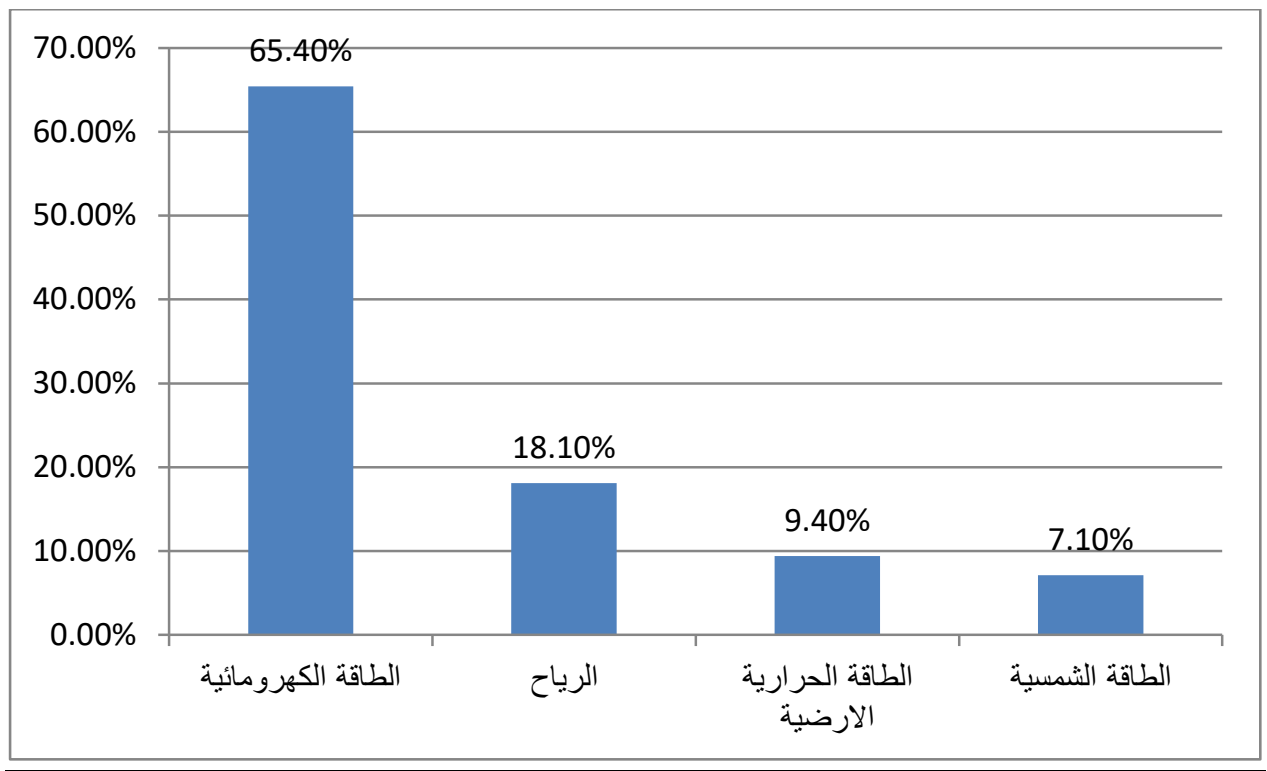

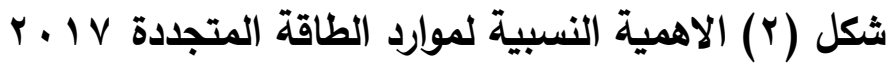

Source: (Elavarasan, 2019:2)

يتضح من الثكل (Y) أن الطاقة الكهرومائية تستحوذ علي النصيب الأكبر في

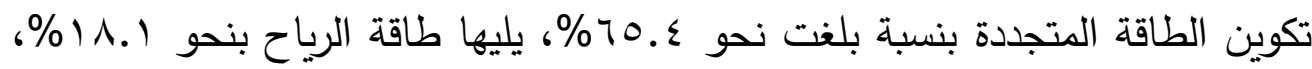
ثم الطاقة الحرارية الارضية بنحو ع.9\% ثم الطاقة الثمسية بنحو ـ٪\%، وهذا يتطلب العمل علي تتمية توليد الطاقة المتجددة من الطاقة الثمسية لاسيما وأنه تم

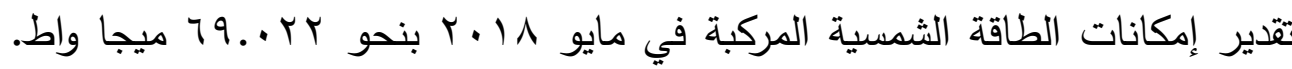
(Elavarasan, 2019:2) وعلي مستوي الدول العربية شهدت السنوات الاخيرة انتشارا واسع النطاق للطاقة المتجددة في عدة دول عربية، لاسيما مع وضع العديد من الاستراتجيات والسياسات التي تركز علي الطاقة المتجددة بالاضافة الي دعم مؤسسات التمويل

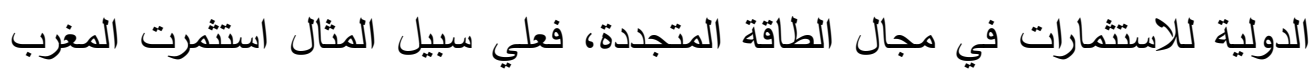
في الطاقة الثمسية وطاقة الرياح بدعم من مؤسسات الاقراض الدولية، وأصبحت المغرب تمتلك أكبر محطة توليد الطاقة من الرياح في أفريقيا وإحدي أكبر محطات الطاقة الثمسية المركزة في العالم، كما أطلقت الحكومة الاردنية الخطة الوطنية في 1 1 ـ ل لاعم النمو الاخضر ، والتي تركز علي قطاع الطاقة المتجدة بوصفها قطاعا 
رئيسيا لتحفيز النمو المستدام، كما تمتلك الاردن محطة الطفيلة لتوليد الكهرباء من الرياح وهي أول مشروع للطاقة المتجددة ينفذ في الاردن بتمويل من القطاع الخاص، بالاضافة إلي أنه يُعد الاول من نوعه الذي يرقي إلي مستوي مرافق الطاقة في الثرق الترق

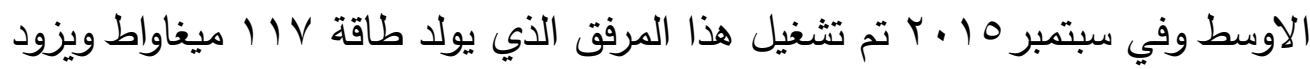

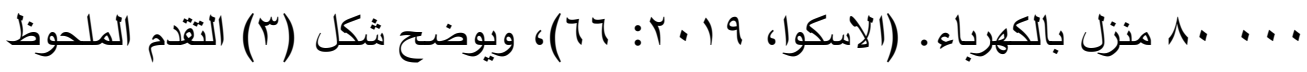
الذي تم انجازه في بعض الدول العربية في مجال توليد الطاقة من المصادر المتجددة.

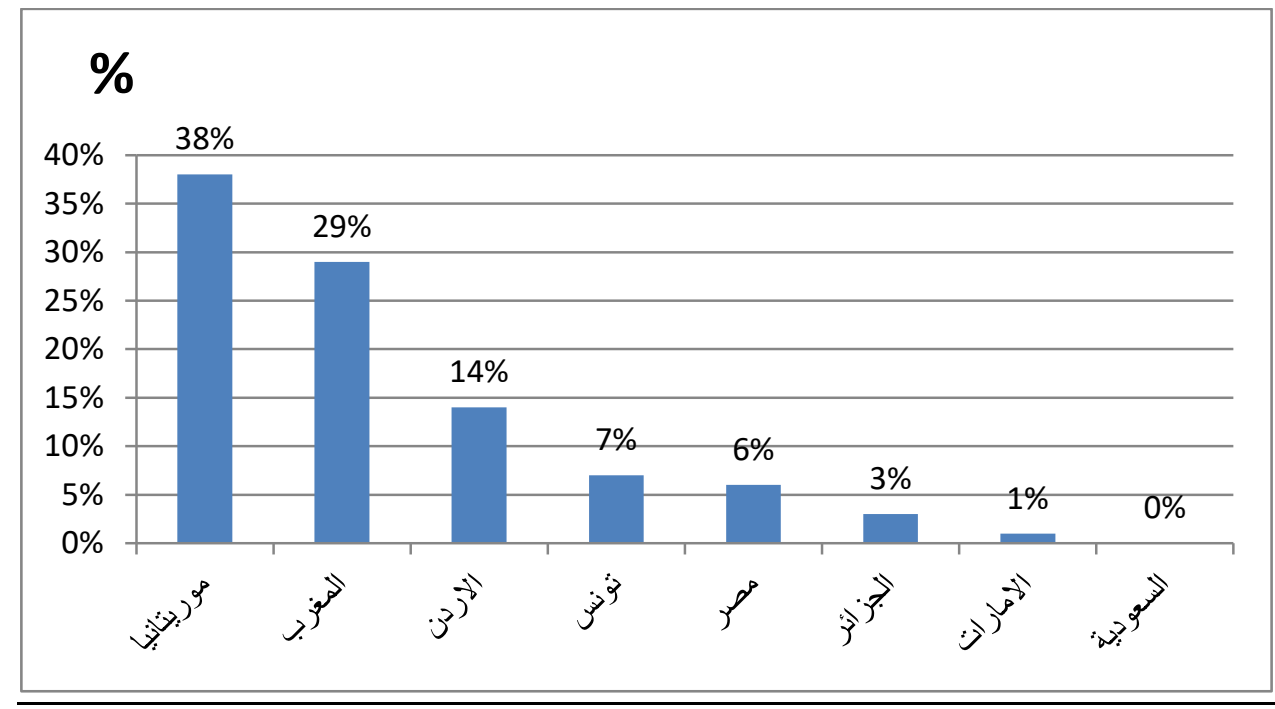

شكل (r) نصيب الطاقة المتجددة من اجمالي توليد الطاقة لعدد من الدول العربية $(r \cdot I V)$

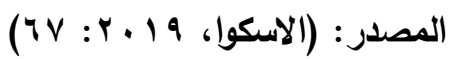

يتضح من الشكل (ب) أن موريتانيا والمغرب والاردن تحتل مراكز متقدمة في مجال توليد الطاقة من مصادر متجددة، حيث وصلت نصيب الطاقة المتجددة من اجمالي توليد الطاقة لنحو ^r\% في موريتانيا ونحو 9٪\% بالمغرب العربي ونحو

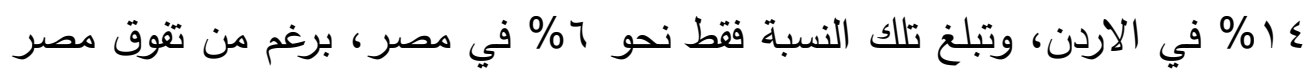

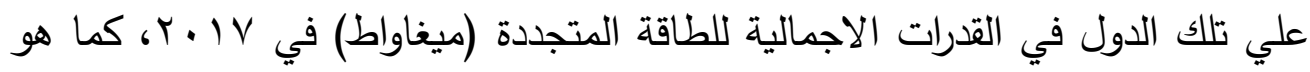

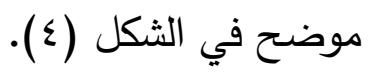




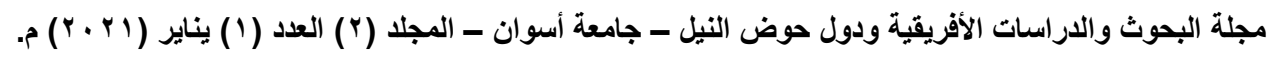

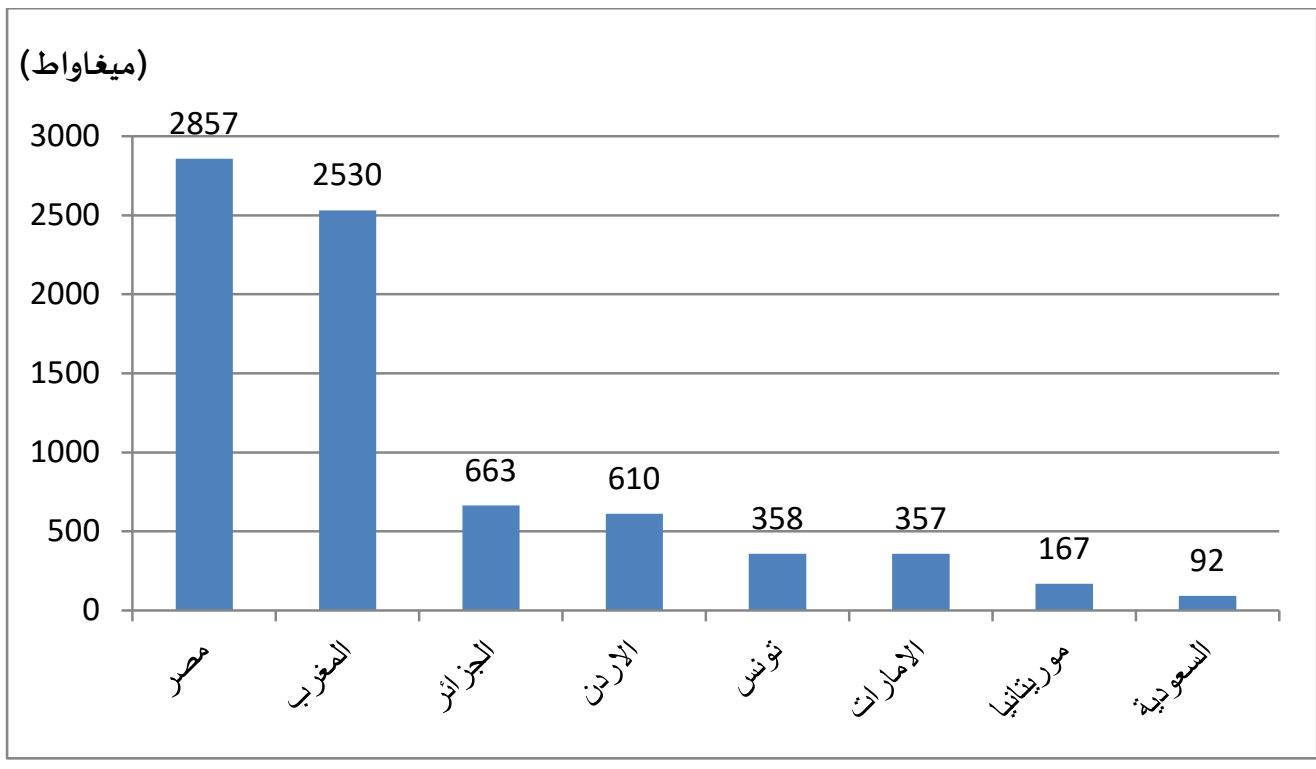

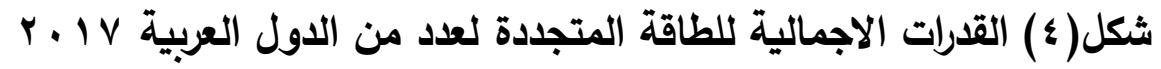

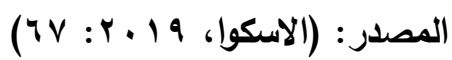

يتضح من الثكل (ع) أن مصر تحتل المركز الاول في مجال القدرات

الاجمالية للطاقة المتجدة، بنحو rAOV ميغاواط، وتحتل المغرب المرتبة الثانية بنحو •ror ميغاواط، فالجزائر في المرتبة الثالثة، يليها الاردن وتونس والامارات وموريتانيا.

والسعودية.

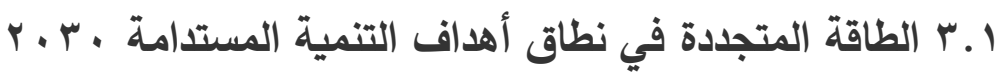

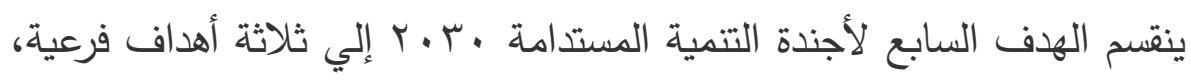
الهدف الفرعي الاول، ضمان حصول الجميع علي خدمات الطاقة الحديثة الموثوقة بتكلفة ميسورة وهو ما يتطلب معرفة نسبة السكان الذين يحصلون علي الكهرباء، ونسبة الاعتماد علي أنواع الوقود والتقنيات النظيفة لأغراض الطهي، وبالنسبة للهدف الفرعي الثاني فيستهد تحقيق زيادة كبيرة في نسبة الطاقة المتجددة من مجموعة

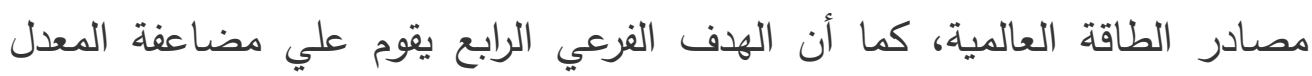
العالمي للتحسن في كفاءة استخدام الطاقة، كما هو موضح في الجدول (1) 


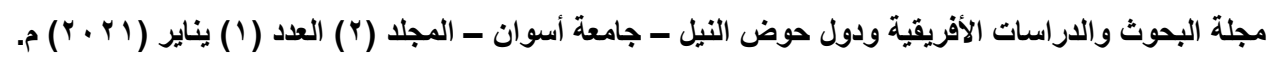

جدول (1) الهدف السابع للطاقة المستدامة مع مجموعة من الغايات والمؤشرات

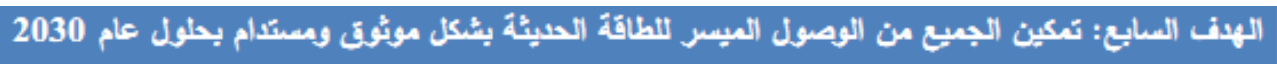

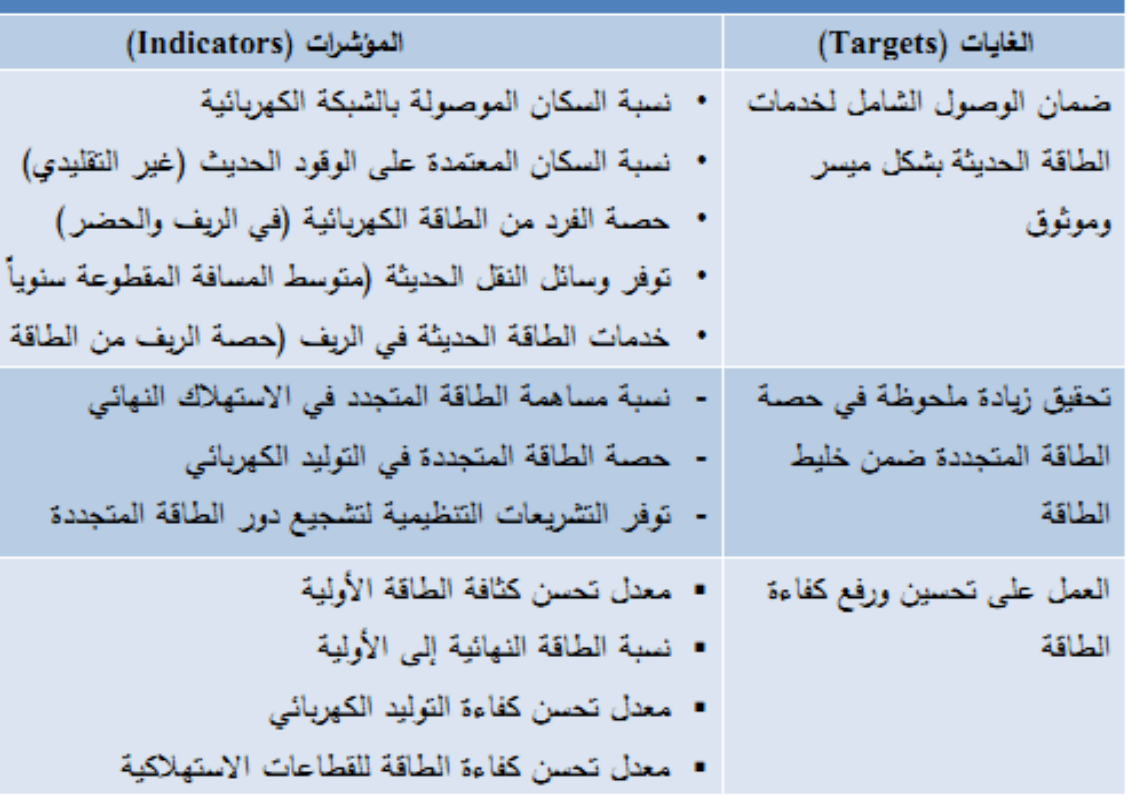

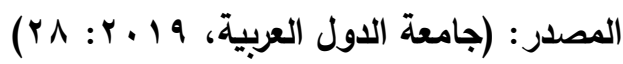

يوضح الجدول (1) أن الوصول لاستراتيجية مستدامة للطاقة وفق الهدف السابع يتطلب توفير الوصول الثامل لخدمات الطاقة الحديثة، ورفع مساهمة الطاقة المتجددة بشكل معتبر في ضمن خليطالطاقة الوطني، وتحسن كفاءة الطاقة. وجدير بالملاحظة أنه في السنوات الاخيرة قد تحقق تقدم واضح في توسيع نطاق الحصول علي الكهرباء في العديد من البلدان، إذ انخفض عدد سكان العالم

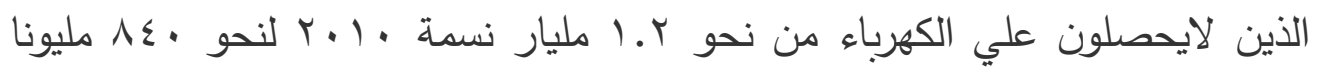
عام V P. P. كما انخفض عدد السكان الذين يفقرون إلي حلول الطهي النظيف من

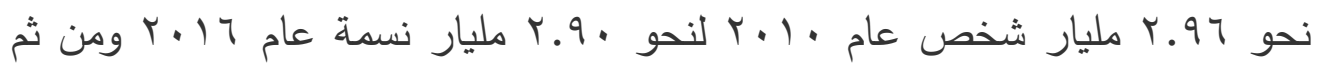
لايزال الاستخدام الواسع لأنواع الوقود وتقنيات الطهي الملوثة يثير مخاوف صحية واجتماعية واقتصادية، كما ارتقعت نسبة الاستهلاك النهائي للطاقة من مصادر الطاقة

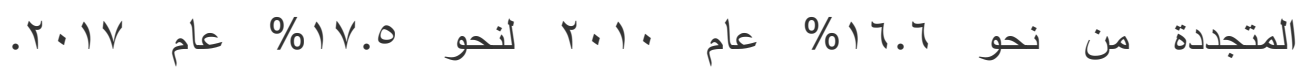
(International Bank for Reconstruction and Development, 2019: 
وفيما يتعلق بكفاءة استخدام الطاقة، فقد بلغت كثافة الطاقة الأولية العالمية

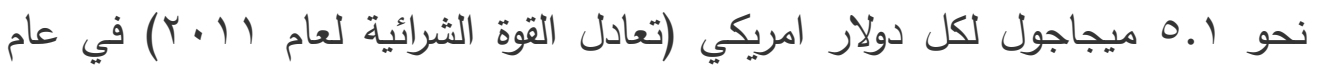
17. 1 ، كما ارتفعت كفاءة تحسينات الطاقة بشكل ملحوظ في السنوات الاخيرة، وذلك بضض الجهود المتضافرة في مجال السياسات في البلدان الرئيسية، ومن بينها الصين. (International Bank for Reconstruction and Development, 2019: 1)

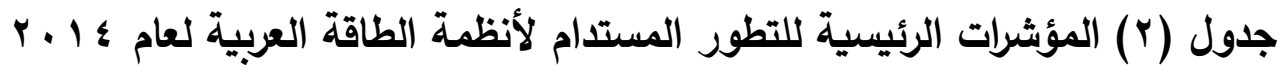

\begin{tabular}{|c|c|c|c|c|c|c|c|c|c|c|}
\hline \multicolumn{3}{|c|}{ كفاءة الطاقة } & \multicolumn{4}{|c|}{ الطاقة المتجددة } & \multicolumn{3}{|c|}{ الوصول الميسر والموثوق } & \multirow{3}{*}{ الدولة } \\
\hline كفاءة & والتقلّ & الطثافة & النهتجدة & والثمسياح & التصئي & اللشبكية & الكتردلاك الكناء & الطنهرداك الطقة & مصنة الناتج & \\
\hline$\%$ & $\%$ & الدو.م.ن/ & $\%$ & $\%$ & $\%$ & $\%$ & ميجاواط & 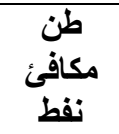 & ألف دولار & \\
\hline 23 & 6.6 & 0.51 & 0.0 & 0.0 & 0.0 & 97.7 & 11.5 & 11.2 & 22 & البحرين \\
\hline 44.9 & 14.7 & 0.37 & 1.5 & 0.9 & 7.9 & 99.4 & 1.6 & 1 & 2.7 & مصر \\
\hline 40.7 & 44.7 & 0.22 & 0.8 & 0.0 & 4.2 & 98 & 1.5 & 1.1 & 5 & العرق \\
\hline 40.7 & 17.3 & 0.37 & 0.1 & 0.0 & 0.3 & 99.4 & 2.3 & 1.5 & 4 & الاردن \\
\hline 33.2 & 11.6 & 0.23 & 0.0 & 0.0 & 0.0 & 97.7 & 16.8 & 8.1 & 35.8 & الكويت \\
\hline 40.7 & 58.8 & 0.23 & 0.2 & 0.0 & 8.7 & 99.9 & 1.2 & 1.7 & 7.3 & لبنان \\
\hline 33.1 & 62.5 & 0.39 & 0.0 & 0.0 & 0.0 & 100 & 1.6 & 2.4 & 6.1 & ليييا \\
\hline 33.5 & 13.6 & 0.43 & 0.0 & 0.0 & 0.0 & 97.7 & 6.3 & 6.8 & 15.7 & عمان \\
\hline 37.9 & 14.7 & 0.43 & 0.0 & 0.0 & 0.0 & 97.7 & 14.1 & 23.1 & 74.6 & قطر \\
\hline 143 & 17.8 & 0.1 & 12.6 & 0.0 & 78.3 & 32.5 & 0.3 & 0.4 & 1.7 & سودان \\
\hline 31.9 & 4.2 & 0.24 & 0.0 & 0.3 & 0.0 & 97.9 & 12.2 & 9.3 & 38.6 & الامارات \\
\hline 23.1 & 36.1 & 0.24 & 0.0 & 0.0 & 0.0 & 48.4 & 0.2 & 0.3 & 1.1 & اليمن \\
\hline 36.1 & 16.5 & 0.29 & 0.7 & 0.4 & 3.0 & 86.3 & 2.3 & 1.8 & 6.3 & العربي \\
\hline 41.5 & 8.6 & 0.19 & 18 & 3.8 & 13.5 & 84.6 & 3.1 & 1.9 & 10 & العالم \\
\hline
\end{tabular}

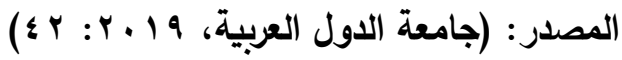

واسترشاداً بمؤشرات الهدف السابع للطاقة المستدامة، يمكن توضيح المؤشرات الرئيسية الحالية لأنظمة الطاقة العربية، حيث تم تقسيم هذه المؤشرات الي ثلاثة مجموعات، تضم المجموعة الاولي عدة مؤشرات تقيس الوصول الميسر والموثوق 
للطاقة، بينما تثتمل المجموعة الثانية المؤشرات المرتبطة بكفاءة الطاقة، أما المجموعة الثالثة فتضم حصة الطاقة المتجدة في مزيج التزود، ويمكن توضيح تلك المؤشرات بالجدول (r) (ب) - (ب)

يتضح من جدول (Y) أن القيمة الوسطي لنصيب الفرد من الناتج المحلي الاجمالي في الوطن العربي والتي تقدر بنحو س.7 ألف دولار أقل بأكثر من نحو من

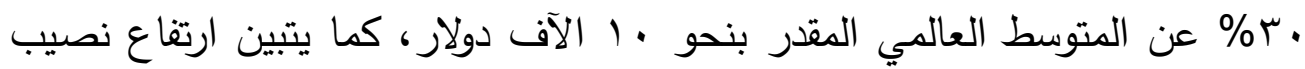
الفرد من استهلاك الكهرباء والطاقة كلما ارتفاع نصيب الفرد من الناتج المحلي الاجمالي كما هو موضح في الشكل (0).

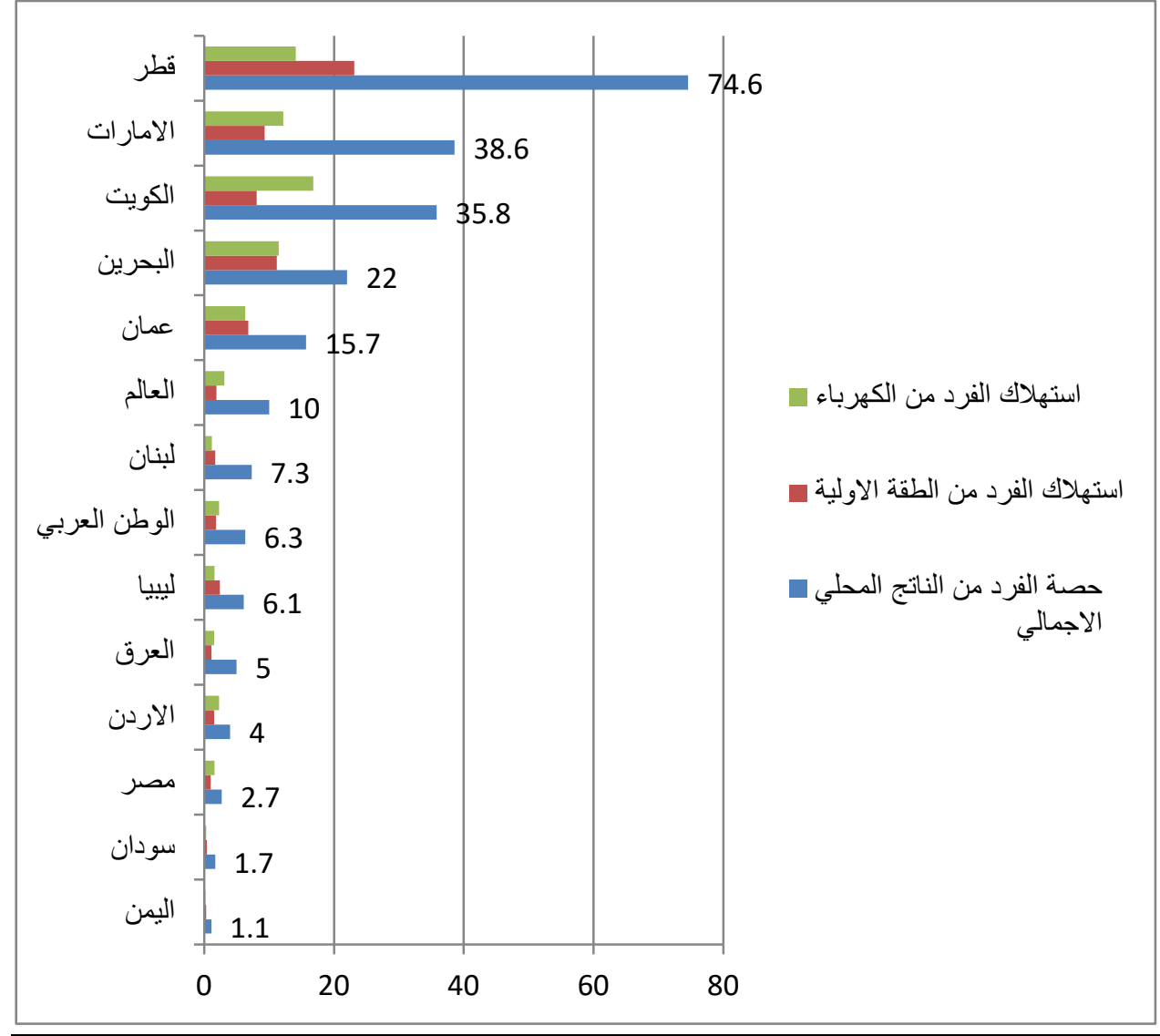

شكل (ه) العلاقة بين نصيب الفرد من الناتج والكهرباء والطاقة الاولية

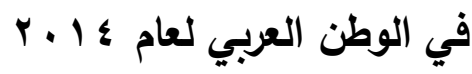
المصدر : تم الاعتماد علي بيانات الجدول (Y-r) 
يتبين من الثكل (0) أن العلاقة طردية بين نصيب الفرد من الناتج المحلي الاجمالي في الوطن العربي واستهلاكه من الطاقة الاولية والكهرباء، فدول مجلس التعاون الخليجي والتي تتنمي فيها قطر والامارات والكويت ذات معدلات الدخل الاعلي تعكس ايضا معدلات استهلاك الطاقة الأعلي علي الأطلاق، علي الرغم من أن الدول الصناعية المتقدمة تمكنت من فك الترابط بين المستوي الاقتصادي ومعدلات استلاكي الطاقة الاولية بفعل اجراءات ترشيد الطاقة وتحسين الكفاءة التي اتخذتها خلال العقود الاخيرة، إلا أنه لايزال الخليج أعلي استهلاكا للطاقة، كما يُّلاحظ وجود تفاوت شاسع في نصيب الفرد من الطاقة الاولية عند مقارنة القيمة العظمي والوسطي كما هو موضح في الشكل (7).

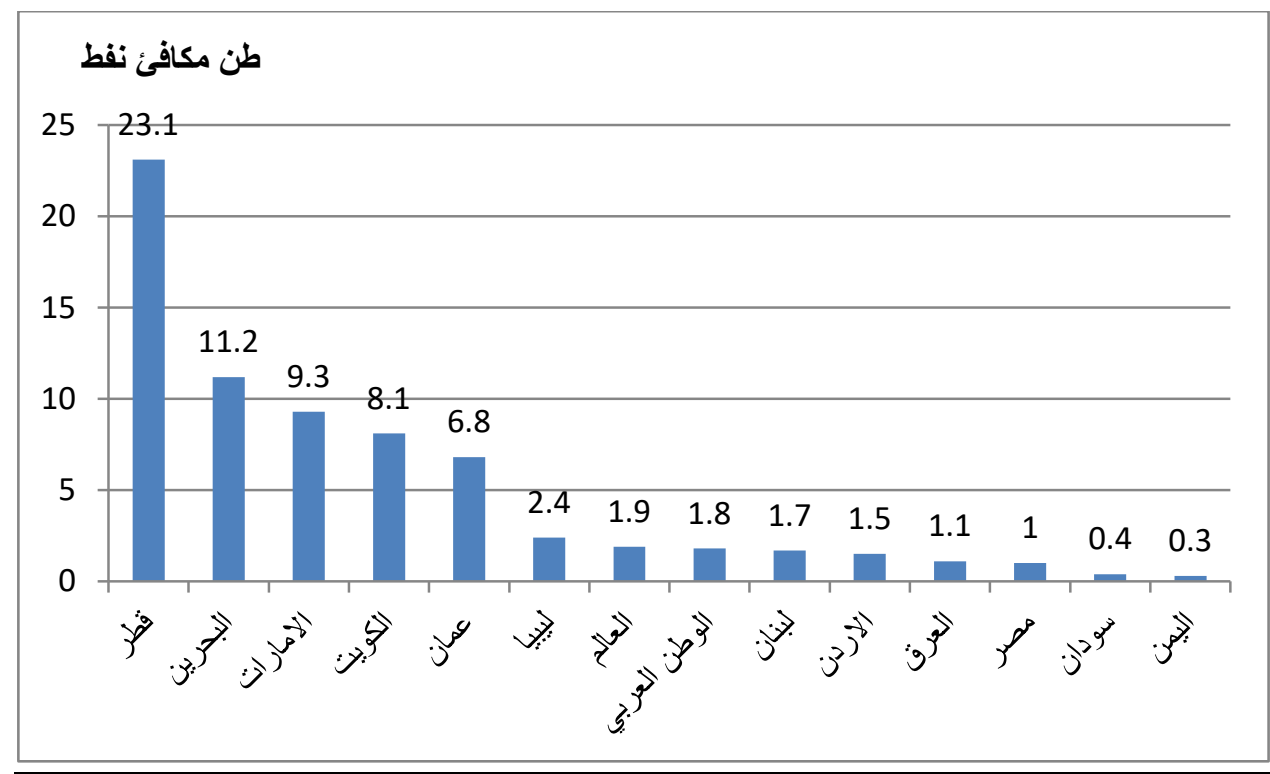

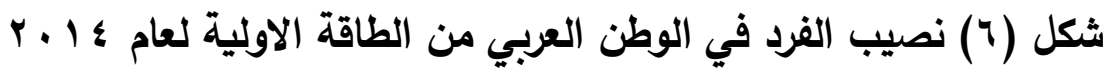

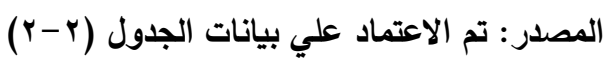

يتضح من الثكل (T) أن هنالك تفاوت كبير في نصيب الفي الفرد من الطاقة الاولية حيث تصل النسبة لنحو VV ضعفا بالنسبة للطاقة الاولية (قطر بالنسبة لليمن)، كما يتبين أن قطر تحتل المرتبة الاولي عربيا من حيث نصيب المواطن من استهلاك بكا 
الطاقة الاولية، ايضا يُلاحظ وجود تفاوت كبير في نصيب الفرد من الكهرباء بين الدول العربية وهو ما يمكن توضيحه بالشكل (V) .

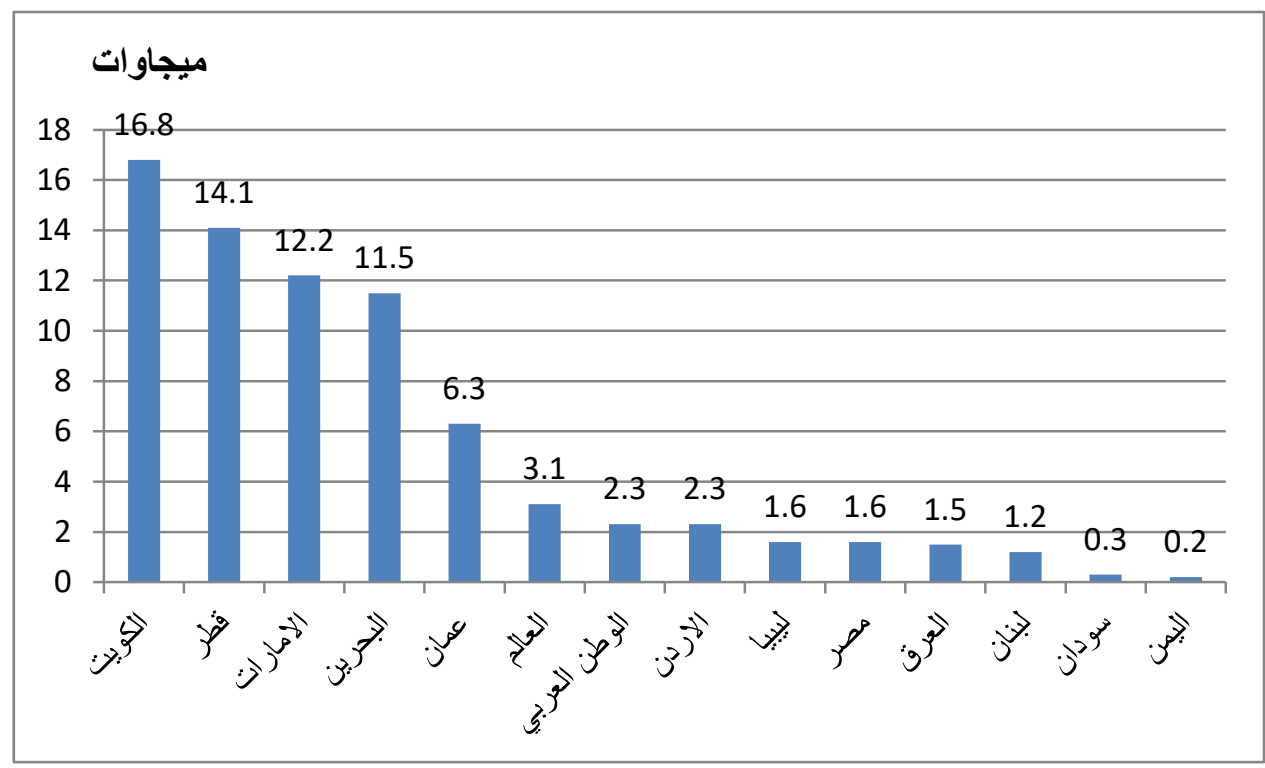

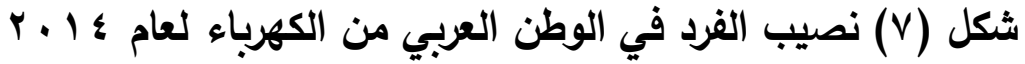
المصدر: تم الاعتماد علي بيانات الجدول (r-r)

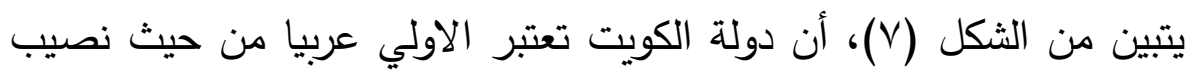
الفرد من استهلاك الكهرباءحيث يستهلك المواطن في الكويت نحو 1. 17 أميجاوات عام ع ا • r مقارنة بنحو r . . ميجاوات نصيب المواطن اليمني من الكهرباء في اليمن أي، نصيب استهلاك الفرد من الكهرباء في الكويت يعادل نحو ع \ ضعف نصيبه في

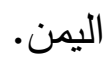
ويتضح من جدول (Y) أن مساهمة الطاقة المتجددة في توليد الطاقة في الدول العربية منخفض للغاية مقارنة بالمعدلات العالمية، فعلي سبيل المثال تسهم الطاقة

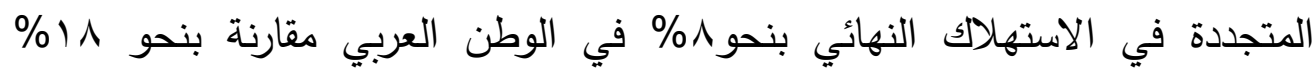

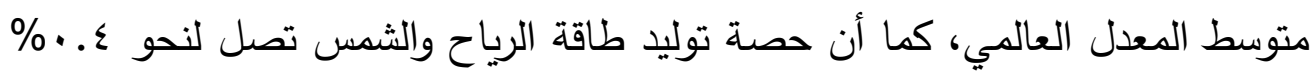


أي، أقل من (\% في الدول العربية مقارنة بنحو ^.r\% مساهمة طاقة الرياح والثمس المتوسط العالمي. وهو ما أدي إلي قيام الدول العربية بوضع الاستراتيجة العربية للطاقة المستدامة • . . ب بغرض مساهمة الطاقة المتجدة وتحسين كفاءة الطاقة، ويوضح

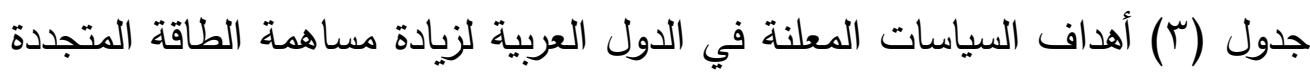
وتحسين كفاءة الطاقة.

جدول (r) أهداف السياسات المعلنة في الدول العربية لزيادة مساهمة الطاقة|لمتجددة وتحسين كفاءة الطاقة

\begin{tabular}{|c|c|c|}
\hline تحسين كفاءة الطاقة وترشيخ استهلاكها & مساهمة الطاقة المتجندة & \\
\hline 20\% من استهلاك الطاقة لكافة القطاعات & 10\% من خليط الطاتة الأولي لعام 2020 & الأرين \\
\hline إصدار ثوانين لأتشجيع ترنشيد وحفظ الطاثة في & 5\% من الطالثة الثهائية عام 2030 (دبي) & 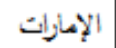 \\
\hline الأبنية & 7\% عن الطاتة التهائية عام 2020 (أبوظبي) & \\
\hline توفيز 17.5 مليين ط.م.ن لغائية عام 2030 & 30\% من القنة المركبة عام 2030 (4 ج.و) & 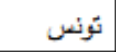 \\
\hline \multirow{6}{*}{ 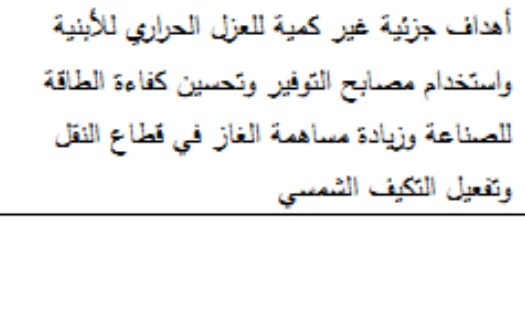 } & 37\% من القنزة المزكبة عام 2030 (22 ج.و)؛ & | الجزائز \\
\hline & وتركيب سخانات شُمبية & \\
\hline & & \\
\hline & & \\
\hline & 9\% من القدرة المزكبة بحلول عام 2023 (9.5 ج.و) & | السعودية \\
\hline & ونلثك كمرحلة أولى ضمن روية المملكة 2030 & \\
\hline توأفيز 15\% من الطلب على انكهباه لغاية 2020 & تركيب 2665 م.و لغاية عام 2031 & المبودان \\
\hline لا يوجد & 10\% من القنزة المزكبة عام 2030 & سورية \\
\hline تخفيض أستهلاك الطاثة عن 5-0| \% لغاية عام & 1\% من القدرة المزكبة عام 2020 & | - العزاق \\
\hline 2020 & & \\
\hline \multirow{2}{*}{ 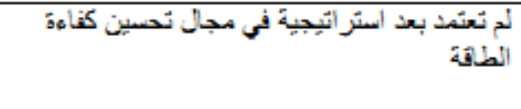 } & بزاسة لنقليل الاعتماد على الطاقة الأحفورية، ودعم & عمان \\
\hline & نشز الطاتة المتجدئة في الريف & \\
\hline خفض أستُهلاك الكهزباء بنسبة 5\% لعام 2020 & 10\% من القنزة المزكبة لعام 2020 & قلسطين \\
\hline \multirow[t]{4}{*}{ خفض استئهلاك الكهزباء بنسبة 20\% لعام 2030} & 20\% من القنزة المزكبة عام 2030 & تطز \\
\hline & 10\% من القنزة المزكبة عام 2030، وصول مساهصة & الكويت \\
\hline & الطالثة الثمسية في القطاع الحكومي إلى 15\% من & \\
\hline & أمتَهلاك الكهزباه عام 2030 & \\
\hline
\end{tabular}

المصدر: (جامعة الدول العربية، 9 ــ ץ: ^^؛) 
يتضح من جدول (r) أن سياسات الدول العربية لتشجيع مساهمة الطاقة المتجدة في توليد الطاقة ورفع كفاءة الطاقة وبما يتقق مع اهداف .ب. • متتوعة في غاياتها ومتباينة في طموحاتها وأفقها الزمني تبعا لواقع هذه الدول وخططها التنموية. ا ـع إجراءات تنويع مصادر الطاقة المتجددة

علي رغم مما تحقق من تقدم ملحوظ في مصادر الطاقة المتجدة خلال العقود الاولي في القرن اب، لاتزال مصادر الطاقة المتجددة تواجه عدة تحديات مالية وتشريعية واقتصادية لضمان استمرار نموها وتوسيع استخدامها عالميا، فتتمية قطاع الطاقة البديلة يتطلب مجموعة من التدابير والاجراءات لتحفيز ونمو قطاع الطاقة البديلة منها، التعاون بين دول المنطقة في مجال الطاقة النظيفة، تعزيز مشاركة القطاع الخاص، بناء القدرات المؤسية، الابتكار التكنولوجي، زيادة تطوير الاسواق، تكثيف الدعم المقدم علي مستوي السياسات. بالنسبة لتكثيف الدعم المقدم علي مستوي السياسات، ويشمل ذلك، سن تشريعات مناسبة وشفافة تتعلق بمنح التصاريح والتراخيص للمستثرين في القطاع الخاص، مواصلة اصلاح التعريفة الجمراكية المفروضة علي الطاقة المحلية، العمل علي اتاحة البيانات والمعلومات، العمل علي ارتفاع الطلب الحكومي علي الطاقة المتجددة في القطاع الحكومي لاسيما المستثفيات والمدارس والمباني العامة حيث تمثل البلدان العربية الاقل نموا سوقا كبير محتمل لتكنولوجيا الطاقة المتجددة اللامركزية والمستخدمة علي نطاق ضيق، ويؤدي تكليف مؤسسة متخصصة بأداء هذه المهمة أن يسهم في تطوير الطاقة المتجددة، من خلال انثاء اسواق متخصصة كسوق للمركبات الكهربائية مما قد يساعد في اعتماد تكنولوجيا الطاقة النظيفة في قطاعات الطاقة في المنطقة العربية.

ويتم تعزيز مشاركة القطاع الخاص، من خلال إتاحة مناخ موات للاستثمار في المشاريع التجارية في مجال تتمية مصادر الطاقة المستدامة للمساعدة في تعزيز ثقة المستثر والحد من المخاطر المرتبطة بمشاريع الطاقة المستدامة، وتخطي العقبات امام الاستثمار، لاسيما التمويل اللازم للاستثمار في مجال التنمية المستدامة، حيث 
ترتفع تكلفة راس المال وتفتقر القطاعات المحلية إلي الادوات المالية المناسبة لتمويل تكنولوجيا الطاقة المتجددة، فشاريع الطاقة المعزولة عن الثبكات تواجه تحديات مثل ضعف التمويل المتاح لها، ومحدوية المعلومات للجهات المانحة للتمويل، لاسيما وان تلك مؤسسات التمويل لها دور هام في تمويل العديد من مشروعات الطاقة المتجددة كما هو موضح في جدول (ع) جدول (؛ ) مشاريع الطاقة الرئيسية الممولة من المصارف الانمائية المتعددة الاطراف والمؤسسات الانمائية

\begin{tabular}{|c|c|c|c|c|c|}
\hline الجهات الممولة & التاريخ & ميفاواط & النوع & الموقم & المشروع \\
\hline الوكالة اليابانية للبعاون الدولي & 2018 & 220 & طاقة الرياح & مصر & هيل الزيت \\
\hline اللانتمادار/مصرف الأوروبي/المصرف الأوروبي الألماني & 2018 & 160 & طاقة الرياح & مصر & جِل الزيت \\
\hline صندوى أبو ظبي للتنمية & 2018 & 103 & الكهروضونية الشمسية & الأردن & كويرة \\
\hline المصرف الأوروبي للإنشاء والتعمير & 2018 & 86 & طاقة الرياح & الأردن & الرجف \\
\hline مصرف التنمية الالالماني للاستثمار/ الأوروبي & 2018 & 170 & الكهروضونية الثمسية & المغرب & الشمطة نور 1 للطاقة \\
\hline مصلي المصارف اليابان للتعاون الدولي/ & 2018 & 350 & الطركاقة الثمسية & المغرب & محطة نور 2 و3 \\
\hline مصرف التنمية الالالماني اللاستثمار/ & 2019 & 250 & طاقة الرياح & مصر & خليخ السويس \\
\hline مصرف النتمية الالألماني للاستثمار/ & 2020 & 300 & طاقة الرياح & المغرب & تسكراد \\
\hline مصرف التنمية الأورلماني للاستثمار/ & 2020 & 150 & طاقة الرياح & المغرب & ميدلت \\
\hline المصرف الأورويي للاستثمار/ & 2020 & 200 & طاقة الرياح & المغرب & جِل الحديد \\
\hline مصرف التنمية الأوروبي للاستئمار/ & 2020 & 100 & طاقة الرياح & المغرب & بوجدور \\
\hline المصرف الأوروبي للاستثمار/ & 2020 & 100 & طاقة الرياح & الهغرب & طنجة 2 \\
\hline
\end{tabular}


يتبين من جدول (ع) أن المصارف الانمائية المتعددة الاطراف والمؤسسات الانمائية لها دور هام في تمويل العديد من مشروعات الطاقة المتجدة، فخلال الفترة

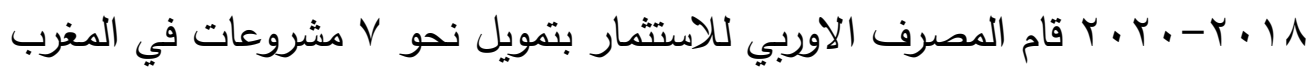
هي، محطة نورا للطاقة الثمسية الكهروضوئية، وفي مجال طاقة الرياح تم تمويل محطة نور Y و r، ومحطة تسكراد، ومحطة ميدلت، ومحطة جبل الحديد، ومحطة

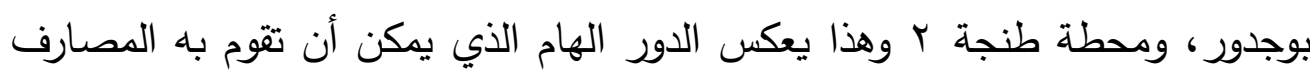
الانمائية المتعددة الاطراف والمؤسسات الانمائية في تمويل العديد من مشروعات الطاقة المتجددة.

كما يتطلب بناء القدرات المؤسية، تعزيز الحوار بشأن السياسات بغية تحقيق

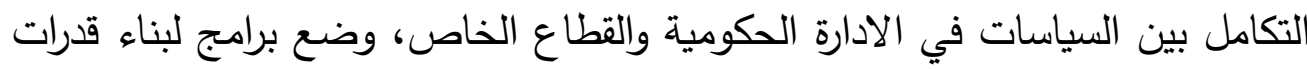

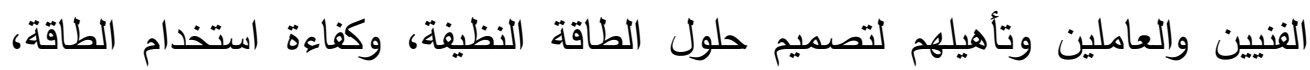
واطلاق حملات توعية داخل المجتمعات في مجال الطاقة المستدامة، وضع برامج تعليمية تستهدف فئة الثباب، وبرامج لبناء اصحاب المصلحة من القطاع الخاص. ويتطلب الابتكار التكنولوجي، الاستثمار في مجال انشطة البحث والتطوير والمشاريع المجتمعية، والتشجيع علي استخدام التكنولوجيا الجديدة، والقابلة للتسويق علي نطاق واسع، مثل المركبات المسيرة بالطاقة الكهربائية، كما في الاقتصاد الاردني، حيث تعفي المركبات الكهربائية من الضرائب والرسوم كما التزامت الاردنية بيناء شبكة تتألف من نحو . . . ب محطة شحن تعمل علي الطاقة الثمسية خلال العقد المقبل. بالاضافة الي أهمية زيادة تطوير الاسواق، لاسيما وان هناك طلب علي الطاقة

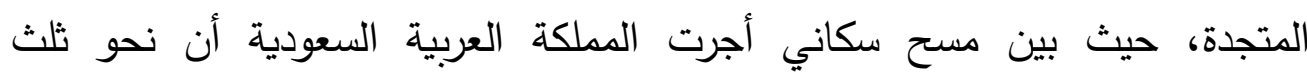
المشاركين يرغبون في شراء الكهرباء المولدة من تكنولوجيا الطاقة المتجددة، وحتي وإن كانت تكلفتها أعلي من تكلفة الكهرباء المولدة من مصادر الطاقة التقليدية. (الاسكوا، .$(\vee \leqslant: Y \cdot 19$

كما يؤدي التعاون بين دول المنطقة في مجال الطاقة النظيفة إلي تتويع مصادر الطاقة أي الانتقال رفع الاهمية النسبية للطاقة المتجددة في ميزان الطاقة 
العالمي، وفي هذا الثأن تم اعتماد الاستراتيجية العربية عام با ـ ب لتطوير استخدامات

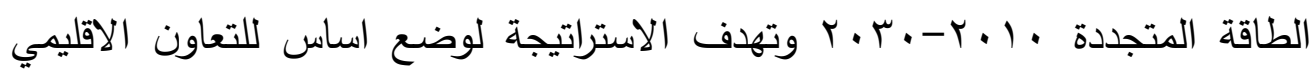
يهدف الي نشر الطاقة النظيفة في المنطقة العربية، كما تهدف الدول العربية لرفع القدرة الحالية لتلك الدول علي توليد الطاقة المتجدة، من نحو با ب جيغاواط عام

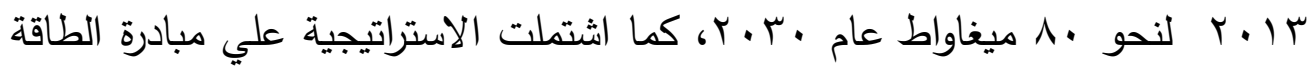
النظيفة لعموم العرب، وهي مبادرة تهدف الي إدماج حصص أكبر من الطاقة المتجددة ضمن نظم الطاقة في المنطقة العربية.

\section{ـ ـ دور البنك الدولي في دعم الطاقة المتجددة}

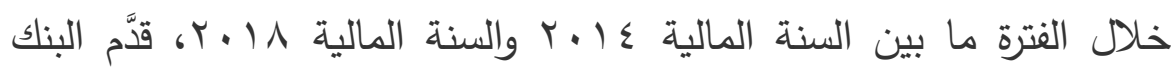
الدولي أكثر من نحو 11 مليار دولار لتمويل الطاقة المتجددة وكفاءة الطاقة، في السنوات الأربع الماضية، كما عزَّزت مجموعة البنك الدولي جهودها لمساعدة البلدان النامية على تسريع انتقالها إلى الطاقة النظيفة في السنوات الأخيرة، من خلال الابتكار في مجالات التكنولوجيا والابتكارات المالية وفي مجال السياسات، حيث قام البنك هـ الدولي في المتوسط بتمويل هب\% من جميع مشاريع الشبكات الشمسية الصغيرة في البلدان النامية، فعلي سبيل المثال في مجال الطهي النظيف والتدفئة النظيفة، يدير البنك الدولي حافظة تضم ما يزيد على ^اب مليون دولار مع برامج في ع ا بلدا بما

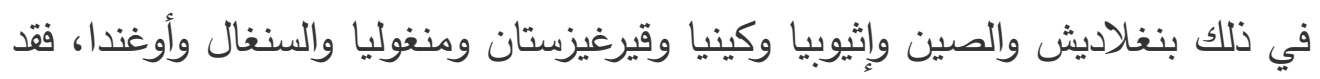
ساعدت هذه البرامج 11 مليون شخص في الوصول إلى حلول بشأن الطهي والتذفئة الأنظف والأكثر كفاءة.(الموقع الاكتروني للبنك الدولي/ فهم الفقر/ أولويات التتمية/

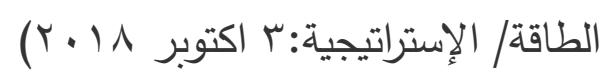

هذا التحول نحو مصادر أنظف للطاقة سيؤدي إلى زيادة الطلب على الركائز المعدنية والمعادن المستخدمة في تصنيع العديد من تقنيات الطاقة الثمسية وطاقة الرياح والتخزين. ويعمل البنك الدولي مع البلدان لتعزيز الحوكمة الرشيدة للقطاعات لمواجهة التأثيرات الناجمة عن التعدين ولضمان التتمية المستدامة والعادلة، وتهتم 
الأبحاث الحديثة والتي اغلبها مدعوم من برنامج مساعدة إدارة قطاع الطاقة، تتبع الهدف V من أهداف التتمية المستدامة، المتمثل في التقدم المحرز نحو الطاقة المستدامة تحديث سنوي بشأن التقدم المحرز على المستوى القطري بشأن أهداف الطاقة المستدامة لعام •.r.r في الوصول إلى الطاقة والطاقة المتجددة وكفاءة استخدام الطاقة، كما يدعم البنك الدولي الشراكات العالمية الاستراتيجية مثل الشراكة العالمية للحد من حرق الغاز وبرنامج مساعدة إدارة قطاع الطاقة، ويوفِّر الأبحاث الأساسية والرائدة والمنتجات الاستثارية والتحليلات الأساسية.

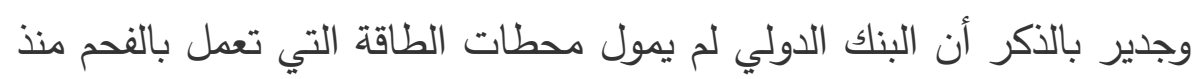

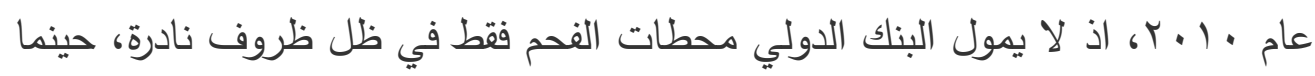
لا توجد بدائل مُجدية لتلبية احتياجات الطاقة الأساسية.

\section{( أخلاصة}

تهدف الدراسة الي شرح الاطار التحليلي للطاقة البديلة، وفي سبيل تحقيق هذا الهدف تم تقسيم الدراسة إلي ستة اجزاء بالاضافة الي المقدمة، حيث يشمل الجزء

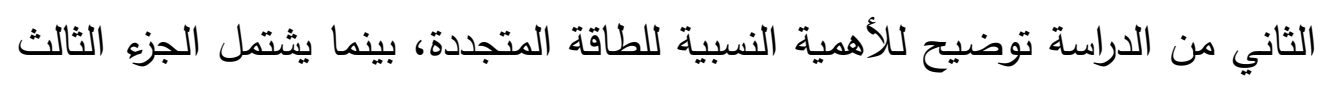

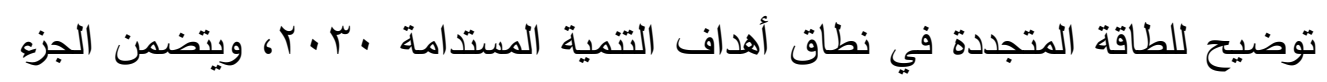
الرابع توضيح لإجراءات ووسائل تنويع مصادر الطاقة المتجددة، ويبين الجزء الخامس علي توضيح لدور البنك الدولي في دعم الطاقة المتجدة، اما الجزء الاخير يتضمن

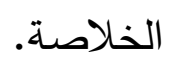

بالنسبة للجزء الثاني الذي تتاول شرح للأهمية النسبية للطاقة المتجددة توصلت

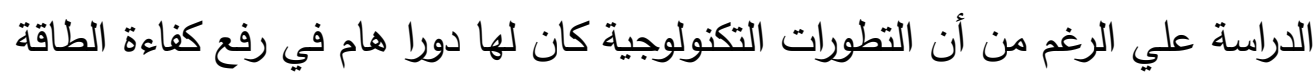
المتجدة، إلا أنه لازال الطاقة المتجددة تسم بنسبة منخفضة في الاستهلاك العالمي للطاقة، كما أن مصادر توليد الطاقة المتجددة لاسيما الطاقة الشمسية والرياح والطاقة الحرارية لازالت تسهم بنسبة محدودة في تكوين الطاقة المتجدة مقارنة بمساهمة الطاقة الكهرومائية في تكوين الطاقة المتجدة. 
أما الجزء الثالث من الدراسة والذي تتاول توضيح للطاقة المتجددة في نطاق

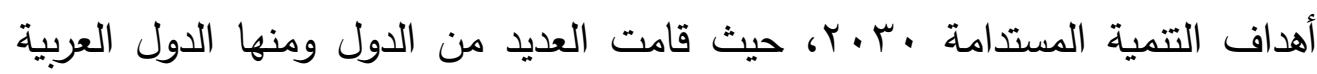

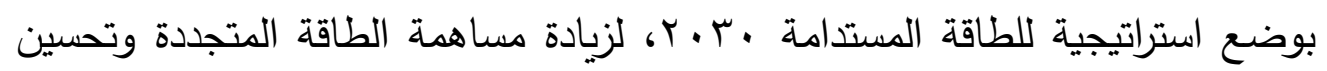
كفاءة الطاقة. كما أن هذه الاستراتيجيات متتوعة في غاياتها ومتباينة في طموحاتها وأفقها الزمني تبعا لواقع هذه الدول وخططها التنموية. وتضمن الجزء الرابع من الدراسة شرح لإجراءات تتويع مصادر الطاقة المتجددة، فعلي رغم مما تحقق من تقدم ملحوظ في مصادر الطاقة المتجدة خلال العقود الاولي في القرن اب، لاتزال مصادر الطاقة المتجددة تواجه عدة تحديات مالية وتشريعية واقتصادية لضمان استمرار نموها وتوسيع استخدامها عالميا، فتنمية قطاع الطاقة البديلة يتطلب مجموعة من التدابير والاجراءات لتحفيز ونمو قطاع الطاقة البديلة منها، التعاون بين دول المنطقة في مجال الطاقة النظيفة، تعزيز مشاركة القطاع

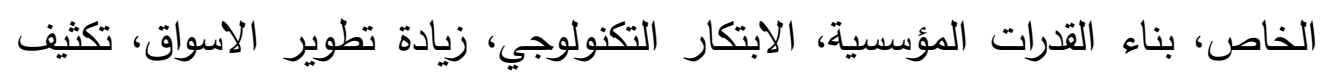
الدعم المقدم علي مستوي السياسات. أما الجزء الخامس اشتمل علي توضيح لدور البنك الدولي، إذ عزَّزت

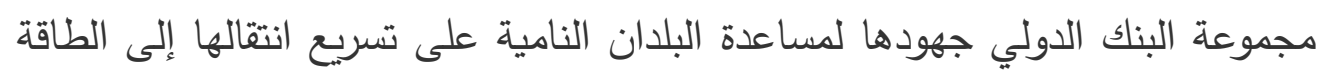
النظيفة في السنوات الأخيرة، من خلال الابتكار في مجالات التكنولوجيا والابتكارات

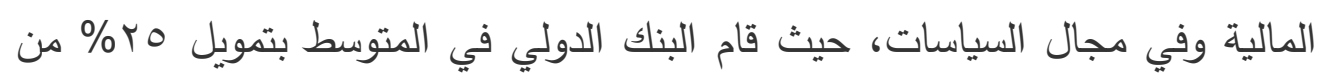
جميع مشاريع الثبكات الثمسية الصغيرة في البلدان النامية، كما يدعم البنك الدولي الشراكات العالمية الاستراتيجية مثل الشراكة العالمية للحد من حرق الغاز وبرنامج مساعدة إدارة قطاع الطاقة، ويوقّر الأبحاث الأساسية والرائدة والمنتجات الاستثارية منية

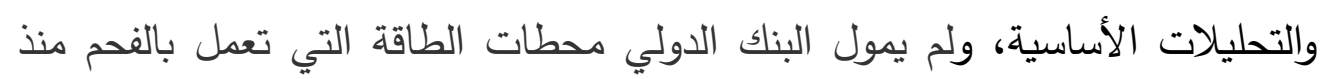

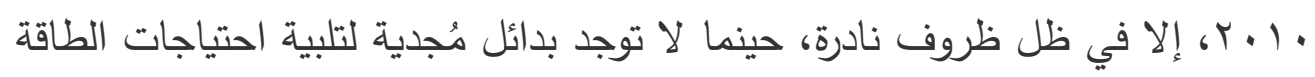
الأساسية، واشتمل الجزء الاخير علي الخلاصة. 


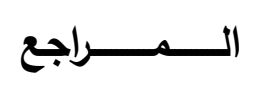

\section{المراجع العربية}

ا. الموقع الالكتروني للبنك الدولي/ فهم الفقر/ أولويات التنمية/ الطاقة/

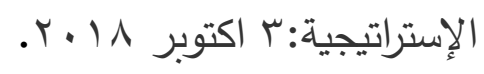

r. الاسكوا (9 ( ب)، "الهشاشة في مجال الطاقة في المنطقة العربية"، الامم

$$
\text { المتحدة بيروت. }
$$

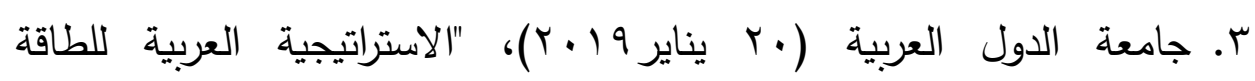
المستدامة •.ץ •.ץ"، القمة العربية التتموية: الاقتصادية والاجتماعية في دورتها

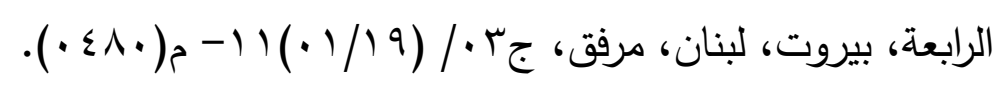

\section{المراجع الأجنبية}

1. Elavarasan, R. M., (2019), "The Motivation for Renewable Energy and its Comparison with Other Energy Sources: A Review", European Journal of Sustainable Development Research, 3(1), em0076.

2. THE WORLD ENERGY COUNCIL, (2016), " World Energy Resources" .

3. UNCTAD, (12 January 2010), " The future energy matrix and renewable energy: implications for energy and food security", United Nations Conference on Trade and Development, 24-25 March 2010 . 